\title{
A Comparative Study on Tapetum
}

\author{
Mamoru lijima \\ The Biological Institute of the Waseda University, \\ Tokyo, Japan
}

Received February 6, 1962

The tapetum or the tissue surrounding the sporogenous cell complex being a tissue in most cases of the same origin as the sporogenous cell complex and in some others of the origin as a morphological composite of tissues of sporogenous cell complex and wall layers as in Ranunculus, its classification was physiological, and the two types, periplasmodium and secretion types are familiar among us. In the former type, the tissue is destined to be deformed and extruded to get distributed among pollen mother cells in meiosis, and in the latter, while the cells show some hypertrophy and often a vacuolization in the cytoplasm, the tissue remains as it is up to the early or somewhat later stage of pollen development.

While the classification into periplasmodium and secretion types is worth being taken as revealing the morphological fate and the physiological role of the tapetum, it implises no problem from the view point of genesis which should greatly relate to the determination of morphological fate, and thus be highly important in a correct comprehension of the whole problem.

While such was and is general situation in the tapetum classification, Cooper (1931) has suggested, without touching much on theoretical problem, that the presence or absence of synchronism in division might serve to be a criterion for new classification of the tapetum. In the present investigation, it is intended to materialize Cooper's view on tapetum classification and to observe the relation between the intended classification and the classical periplasmodium-secretion classification. The question on the physiological role of tapetum tissue is out of the scope of the present investigation.

\section{Material and method}

The material was fixed with Bonn-Flemming solution and stained with iron haematoxylin. The plants observed are as follows: Tradescantia reflexa, Rumex acetocera, Paeonia albiflora, Pinus Thunbergii, Viscum album, Trillium Kamtschaticum, Bletilla striata, Cryptomeria japonica, Alstroemeria spiralis, Lilium speciosum, Nicotiana sp., Sagittaria Aginasi, Vicia Faba, Oenothera Lamarckiana and Equisetum arvense.

\section{Description}

After the differentiation as tapetum, the tissue cells divide once or twice 
in the period of time of meiosis in taking place and sometimes more times. The first division of the tapetum cells is usually observed at about the synizesis stage of meiosis. A second division may follow or may not, it being different in different species. If second division follows, it takes place during the proceeding of the prophase I of meiosis. A third division may follow in still other species.

In the present investigation we observed three different cases in respect to the synchronism in division. In the first case, the tapetal cells are divided synchronouly, though there are some variations in degree of synchronization, namely that while in one case the division is perfectly synchronized in respect to every stage of division, in others the stage may differ in different cells from prophase to telophase. Those cases where all cells are in division stages are called synchronized type in this paper, irrespective of whether or not synchronism is also observed in the stage of dividing cells.

In the second case, only some small number of cells of the tissue are in division, and the remaining majority of cells are in resting stage. In this case the tissue is, so to speak, a mingled composition composed of dividing and resting cells. In this case, division stage is different in different dividing cells. We shall call this case asynchronized type.

In the third case which may expediently be called intermediate type, the tissue is a mingled composition of dividing and resting cells as in the asynchronized type, but characterized from it by the number of dividing cells being greater than resting cells and also by the fact that division stages often show some tendency of converging toward a definite dividing stage or tendency of stage synchronization.

The following descriptions are based on the results obtained by observation of sections of material.

\section{A. Synchronized type}

In this type, the first division is synchronized and takes place in the period of about leptotene or synizesis of meiosis. The division is normal excepting that in most cases no cell membrane is formed. The resting cells are thus binucleate or polyploid in constitution. The second division follows then and is usually followed by ensuing divisions that continue to take place. In this type there are found both periplasmodium and secretion types. Tradescantia reflexa, Rumex acetocera, Paeonia albiflora and Pinus Thunbergii were observed to belong to this type.

Tradescantia reflexa. The first division takes place at about late synizesis synchronously. When prophasic figure is observed or metaphasic figure is observed, all the cells belonging to one loculus are in prophase or metaphase according to the cases observed (Fig. 1). When anaphasic figure is observed, all the cells are in anaphase, those in the basal region of the anther being excepted in this case, where telophasic cells are often found mingled. This difference between the cases of metaphase or prophase and anaphase 
seems to depend upon the difference in speed of proceeding from one stage to the next.

The tapetum cells then come to extrude into the cavity of loculus at
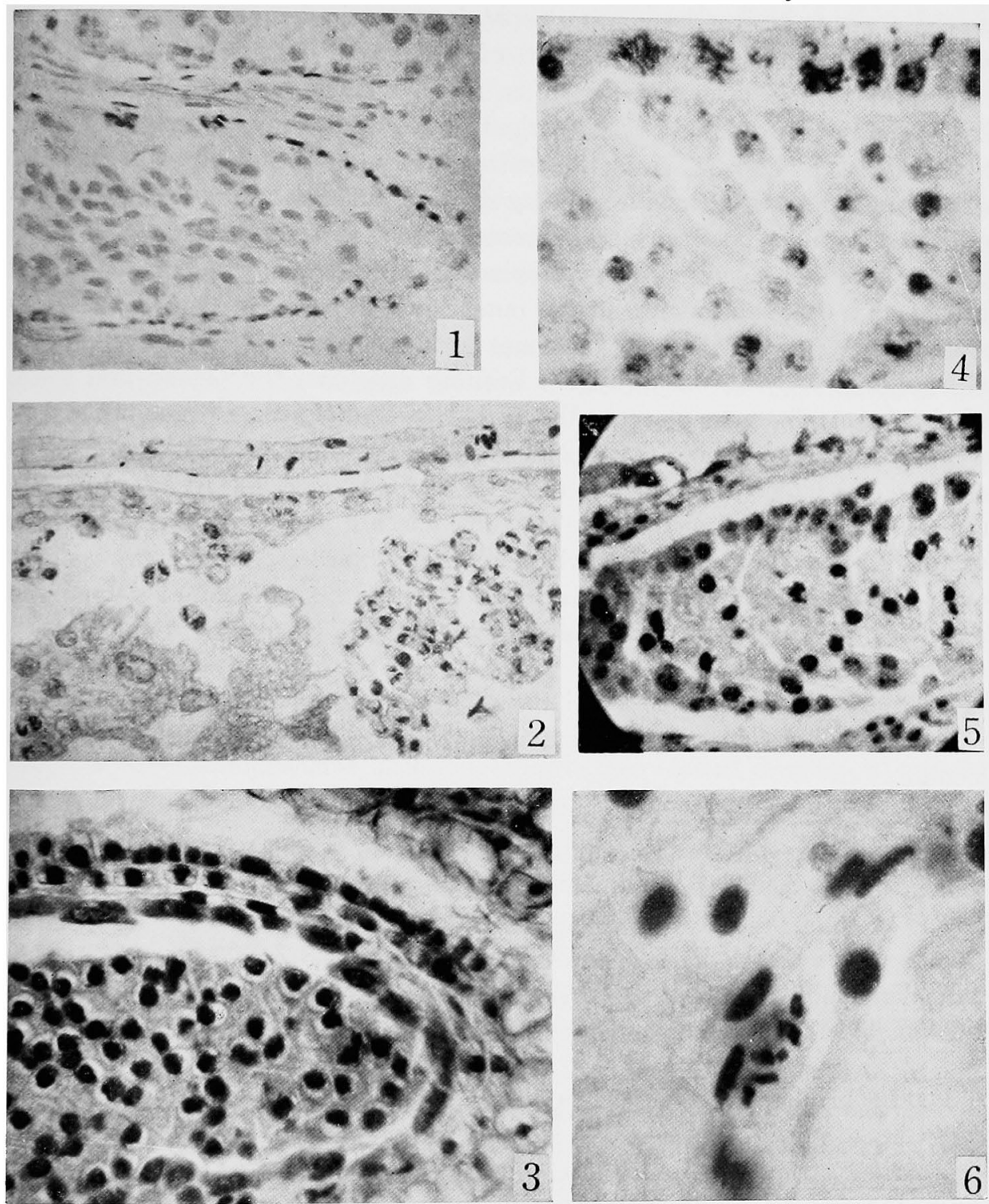

Figs. 1-6. 1, tapetum cells of Tradescantia reflexa are all in anaphase. 2, tapetum cells of Tradescantia reflexa in second meiotic division. 3, tapetum cells of Rumex acetocera are all in late prophase, while the pollen mother cells are in synapsis. 4, tapetum cells of Paeonia albiflora are all in mitotic stages, mainly in late prophase or in metaphase. 5, tapetum cells of Viscum album. 6, a metaphasic figure of tapetum cell of Viscum album, in which the chromosomes are very short and not in normal slender forms.

the stages from diplotene to metaphase I of meiosis. The second and third divisions take place during the extruding stage, asynchronously in these cases. 
Some tapetal cells may naturally remain attaching to the wall layers as shown in Fig. 2.

The innermost parietal layer which is in this plant of the same origin as the tapetum tissue show hypertrophy in a certain degree at about the stage of ending of meiosis. At the period of the second division of meiosis, the innermost parietal layer cells are often found to be in division. In the period from interkinesis to second division, the tapetal cells mostly undergo autolysis.

Rumex acetocera. In leptotene stage of meiosis, the tapetum cells are all in resting stage. In synizesis they divide, and synchronously. The synchronization is of perfect performance as in Tradescantia. In Fig. 3, all tapetal cells are shown to be in prophase. A transversal section shows that the tapetum tissues belonging to the outer loculi are in the stage of development in advance of those of the inner loculi. This is the case common to other species of synchronized type. Ensuing divisions, the second and third, of tapetum cells take place in the period from diplotene to metaphase I of meiosis. In later stages, the tapetal cells show a hypertrophy, but no such extrusion phenomenon takes place as we have observed in Tradescantia. In the second division of meiosis, the tapetum cells are observed to be binucleate or characterized by carrying a giant nucleus within. The cytoplasm shows one or two vacuoles in it. Rumex tapetum is the case of secretion type and remains in its form until the stage of pollen development.

Paeonia albiflora. The synchronization in the first division of the tapetal cells is not very conspicuously marked in this species. Fig. 4 shows a case where figures of late prophase and metaphase are found mingled in the same loculus.

Pinus Thunbergii. The division figures of the first division found at a loculus cover almost whole mitotic stages from prophase to telophase. All cells belonging to one loculus are in division, but stages are different among cells. In this species, we may speak of synchronism only in a loose sense. The second tapetum division takes place during the first meiotic division in this plant. This is also the case with Paeonia. In both these plants, the tapetum is of periplasmodium type.

B. Asynchronized type

In this type, the division takes place separately one after another in random distribution. There are found only a few mitotic figures in a section. The first division takes place in the period of time from leptotene to streptotene, and seldom it continues up to the first metaphase of meiosis. The second division is not observed in this type. All species belonging to this type are observed to be of the secretion type without exception. Viscum album, Trillium Kamtschaticum and Bletilla striata were observed.

Viscum album. In this species, the first division is found only in a few cells. Usually, one to three cells are observed in a cross-section to be in mitosis. The period of occurrence of division ranges from leptotene to 
late prophase I of meiosis, but seldom the division is observed even at the metaphase I (Fig. 5). The mitosis is normal. The divided cells grow and show hypertrophy in a high degree. The chromosomes appear to be short and are not of so a slender form as in normal somatic division, though this is not general characteristic of tapetum tissue (Fig. 6). The second division does not take place.

In this species, the tapetum is the typical form of secretion type, and remains as such during the young pollen stage. Pisek (1923) reported that this plant had no tapetum, but the present investigation shows that it has one. Cryptomeria $s p$., too, was believed by Lawson to be devoid of tapetum, but in Cryptomeria japonica we have observed that it exsists remaining in its form until the young pollen stage.

Trillium Kamtschaticum. The first division occurs about the synizesis stage of meiosis. The second division is lacking. The tapetum is of the secretion type.

Rletilla striata. The first division takes place about the synizesis stage or more less earlier. The second division is lacking. The tapetum is of the secretion type.

\section{Intermediate type}

This type is distinguished from asynchronized type by some stronger tendency toward synchronization. Among those we observed, Vicia Faba and Oenothera Lamarckiana were found to be the species in which synchronism was shown in lowest degree in the type (Fig. 7). In this type, two subtypes are distinguishable according to whether second division is present or absent. Alstroemeria spiralis, Lilium speciosum and Nicotiana sp. are those of subtype I in which second division takes place, and Sagittaria Aginasi, Vicia Faba, Oenothera Lamarckiana and Equisetum arvense are those of subtype 2 which are lacking the second division. So far as the presence or absence of second division is concerned, subtype I is to synchronized type characterized by the occurrence of second division, and subtype 2 to asynchronized type lacking this division. In this respect the intermediate type is a mixed type.

The developed form of tapetum is of periplasmodium type in subtype I, and secretion type in subtype 2, except for the case of Equisetum in which the secretion type tissue assumes a periplasmodium form in its later stage.

Subtype I. Alstroemeria spiralis. The first division is observed at about the stage of synizesis. The division figures which are observed in a random distribution among resting cells show a stage-synchronization in loose sense. The division is abnormal already in the first division. This seems to be a particular phenomenon, since in other plants which we have observed, the first division is always normal except for the case of cell membrane formation. In this plant, tripolar and multi-polar division figures, and especially to be 
mentioned, such figures as reminding of "eckige Kerne" are often observed (Fig. 8).

In the period of pachytene stage, binucleate cells are observed. The second and third divisions take place in the period of later stages of meiosis. The division is abnormal in these cases, too 1 .
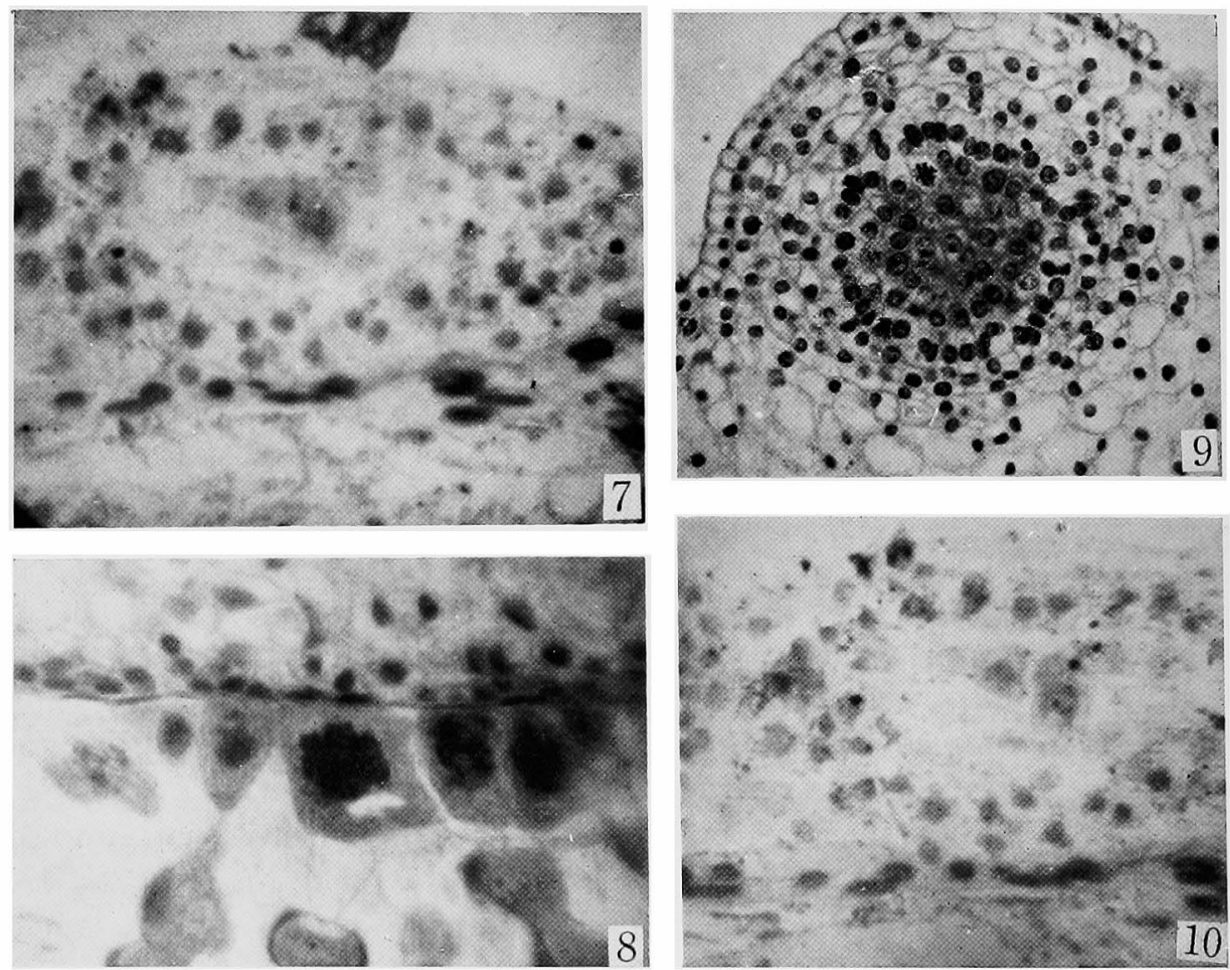

Figs. 7-10. 7, tapetum cells of Oenothera Lamarckiana are in mitosis in some cells. 8, tapetum cells of Alstroemeria spiralis showing "eckige Kerne". 9, tapetum cells of Lilium speciosum are in mitosis in two cells. 10, tapetum cells of Vicia Faba showing mitotic figures.

The tissue extrusion of the tapetum into the loculus takes place, in this plant, in a particular manner of forming wavy contour, without advancing as far as projecting into between pollen mother cells. The tapetum cells show often vacuoles in the cytoplasm, and remain as they are until the young pollen stage. In this plant, the tapetum appears to be of secretion type before the final stage is reached.

It is a remarkable fact that in this plant some mitotic figures are observed here and there in the wall tissue during the proceeding of meiosis. In other plants which we observed, mitotic figures were only seldomely found in the wall tissue in the period of meiosis in performance.

Lilium speciosum. The first division is of the precocious occurrence.

1 To be published later in detail. 
It is observed before the last premeiotic division (Fig. 9). After the first division, the tapetum cells are all binucleate and contain a large vacuole in each.

In the period after pachytene, second and third divisions are observed here and there among resting cells. The tapetum tissue remains in its form still in the young pollen stage.

Subtype 2. Vicia Faba. First division is observed in the period of early synizesis, or more or less earlier. Some several division figures of stages from early metaphase to anaphase are found in one section among resting cells (Fig. 10). There is a synchronization in loose sense in the first division. The daughter nuclei often fuse together and form a giant nucleus. No second division takes place in this plant.

The tapetal cells show hypertrophy during later stages of meiosis and the nuclei grow larger in size. The cytoplasm is remarkably vacuolated. The tapetum with thus characterized cells remain in tissue form till the young pollen stage.

Sagittaria Aginasi. In this plant, the first division is of asynchronized type, and no second division takes place.

Equisetum arvense. The tapetum tissue forms several small chambers in the loculus, so as to divide a mass of pollen mother cells into groups and to embrace each group in each chamber. This projection of the tapetum into the loculus occurs during the period of some earlier stages of meiosis. The tapetum tissue becomes degenerated in meiosis. No second division takes place.

Oenothera Lamarckiana. The first division of the tapetal cells takes place during the synizesis stage of meiosis. The division is synchronous though in the very loose sense. The second division is lacking, and the tapetum is of the secretion type.

\section{Discussion}

The tapetum cells divide still after they differentiated into tapetum tissue, synchronously or asynchronously. The behavior in synchronization and the number of times of division are different in different cases. The results we obtained in the present investigation are summarized as follows:

1. Synchronized type (plants observed; Tradescantia, Rumex, Paeonia and Pinus). The first division (strictly speaking, divisions) shows a remarkable synchronism. The second division takes place with a less pronounced synchronism. In certain plants (Tradescantia and Rumex), a third or a fourth division may follow which are also less synchronous. In most cases the final form of the tapetum is of periplasmodium type, but in a few it is of secretion type.

2. Asynchronized type (plants observed; Viscum, Trillium and Bletilla). The first division takes place asynchronously in this type. The second 
division never takes place. In all cases the final form is of secretion type. No single case of periplasmodium type is found.

3. Intermediate type. In this type, dividing cells are found in greater numbers than resting cells as opposed to the asynchronized type in which they are in smaller number than the latter. In this case, two subtypes can be distinguished.

Subtype 1 (plants observed; Alstroemeria, Lilium and Nicotiana). In the first division, dividing cells show some tendency of stage synchronization. Second division always follows. In most cases the final form is of periplasmodium type, but in some it is found to be of secretion type.

Subtype 2 (plants observed; Sagittaria, Vicia, Oenothera and Equisetum). First division is of asynchronized type ; namely, dividing cells show no tendency of stage synchronization. There is no second division to follow in this case. All are of secretion type except the case of Equisetum, where a layered tissue comes to undergo the change into the condition of periplasmodium type.

From these results we obtained, it seems likely that the differential development of tapetum into two final forms, periplasmodium and secretion types, is largely connected with the growth in bulk of the tapetum tissue. When the growth is limitted by the suspension of divisions after the first division, the tapetum is mostly of secretion type, and when it goes on by ensuing divisions, it is of periplasmodium type in most cases.

The present investigation is an attempt of materializing Cooper's view on classification in which the synchronism in division is to be taken as criterion. What is meant by the synchronization in this case? It would be the question which we should have to consider first, to draw a conclusion on the problem.

The germ cells are characterized by two distinct features, by their genesis by synchronized divisions and by their independent state free from one another or lacking the tissue forming character. And, the tapetum is of the sporogenous cell complex origin, even the case of the morphological composite of tissues, too. The tapetum cells, though endowed with somatic characters, are originally of generative cell nature. This origin of the tapetum will probably explain the question, how it is characterized by division synchronism in certain cases so manifestly that all cells are in division, all even proceeding with the same stages. These cases would probably be those where the original characters are strongly retained, and we could naturally expect cases where the endowed somatic characters are more strongly manifest than the original characters. In the latter cases, the division will take place asynchronously. In the case of synchronized type, too, the synchronism becomes less remarkable, when somatic nature is rendered more manifest by a further tissue development through second and third divisions. Analogous cases are found in the ontogenetic development from an egg, and especially manifest 
in the development of angiospermous endosperm or "second embryo" of abortive existence or existence put apart from the somatic differentiations.

Now, we may regard the synchronism as involving in it that by it two classes, one comprising those cases of stronger tendency toward somatic characters and the other those of stronger tendency of retaining original characters, can be distinguished. This syn-asynchronism classification would be more morphological than the classical periplasmodium-secretion classification which refers only to developed or final forms and is largely physiological in view point. And yet, we see that the two classifications are in coincidence in effect, namely: the synchronized type is mostly destined to be periplasmodium type and the asynchronized type to secretion type. The reason of this coincidence seems to rest on the ground that in tapetum the tissue forming tendency as an endowed somatic character is comparatively weak in intensity and only so far rigid as the tissue development is limitted to a certain small extent as in secretion type. When the development goes beyond this limit, deformation may result-an occurrence of periplasmodium type.

A further question which must be answered for a clearer understanding of the coincidence of the two classifications is how the case of the type of synchronized division of generative character can continue tissue growth, while in the case of the type of asynchronized division of somatic character the growth ceases to take place after the first division. This is a difficult question to be answered. An available answer would probably be that in the tapetum as of sporogenous cell complex origin there must in any case be some remarkable tendency of converting into a tissue of genuine somatic nature. If the synchronism is not a somatic character as we assume it, in the synchronized type the tapetum would obtain its somatic character only by its synchronism retained as anti-somatic character being compensated by continuing tissue growth which is pro-somatic character, while in the asynchronized type which converted more fully into somatic nature such a compensation is unnecessary, hence in this case a further division may cease to take place.

Above, we discussed the problem from a general point of view. As a matter of fact, however, there are intermediate cases or exceptional cases, where a case belonging to one type or tending to be so on account of its possessing in a more or less degree of the characteristic taken arbitrarily as clearly distinguishing the type, shows to carry some subordinate characteristics belonging to other type (Table 1). The two types are, then, connected by these characteristics intertwinning one type with another. They represent only two extreme cases-synchronized and asynchronized types or periplasmodium and secretion types, and the whole is of the nature of being theoretically undividable. Such seems to be rather natural to suppose for that case of tapetum, when we consider it to be a complex of new tendencies toward somatic nature from its original nature of generative functions. The 
transformation from a complex of tendencies into another would hardly take place in clear cut form. Our classification is in each class only to refer to a certain tendency which is pronouncedly expressed, and thus the classes classified appear to be distinct from each other. But, the classification is in

Table 1. Summary tabulated of the results obtained

\begin{tabular}{|c|c|c|c|}
\hline & \multirow[t]{2}{*}{$\begin{array}{c}\text { Synchronized Type } \\
\mathrm{D}(+++)\end{array}$} & $\begin{array}{c}\text { Intermediate Type } \\
\mathrm{D}(++)+\mathrm{R}(+)\end{array}$ & \multirow[t]{2}{*}{$\begin{array}{c}\text { Asynchronized Type } \\
D(+)+R(++)\end{array}$} \\
\hline & & Subtype $1 \quad$ Subtype 2 & \\
\hline First division & $\begin{array}{c}\text { Total division synchro- } \\
\text { nization } \\
(++) \\
\text { Total division synchro- } \\
\text { nization } \\
(+)\end{array}$ & $\begin{array}{l}\text { Synchronizing } \\
\text { tendency } \\
+\quad\end{array}$ & $\begin{array}{c}\text { Synchronizing } \\
\text { tendency } \\
-\end{array}$ \\
\hline $\begin{array}{l}\text { Second } \\
\text { division }\end{array}$ & + & + & - \\
\hline $\begin{array}{l}\text { Type of final } \\
\text { form }\end{array}$ & $\begin{array}{c}\text { Periplasmodium } \\
(++) \\
\text { Secretion } \\
(+)\end{array}$ & $\begin{array}{l}\text { Periplasmodium } \\
(++) \\
(+) \text { Secretion } \\
(++)\end{array}$ & $\begin{array}{l}\text { Secretion } \\
(+++)\end{array}$ \\
\hline $\begin{array}{r}\mathrm{D} \\
\mathrm{R} \\
+ \\
(+++) \\
(++),(+) \\
(++) \\
-\end{array}$ & $\begin{array}{l}=\text { cells in division. } \\
=\text { cells in resting stage. } \\
=\text { presence. } \\
=\text { all cells or cases in or } \\
=\text { some cells or cases in } \\
>(+) . \\
=\text { absence. }\end{array}$ & of & \\
\hline
\end{tabular}

reality simply a formal and artificial in nature. The same is also true for the periplasmodium-secretion classification. The two classifications alike are essentially artificial. This state of affairs in classification standing on actual facts is nothing else than what tells the true nature of the tapetum. The tapetum would be the product of counteractions between tendencies of retaining original nature and differentiating from it.

The syn-asynchronism classification is the classification in which the retaining tendency is taken as criterion, and the periplasmodium-secretion classification is that in which converted tendency serves as criterion. They are different in the view point of classification, but equally artificial in the sense that an undividable whole is artificially divided.

If the tapetum is a steril form of sporogenous cell complex and clearly to be distinguished from the genuine somatic tissues, it should have some properties common to sporogenous cell complex. We have some data to show this :-

In Litium anther, the tapetum cells, oxidize Nadi-reagent and reduce 2-6-dichlorophenol-indophenol and $\mathrm{Na}$-nitroprusside, as equally as sporogenous cells do as distinguishing them from somatic cells, in the period of stages of 
premeiosis and meiosis. In the case of meiotic stages they show again the same behavior as sporogenous cells in oxidizing the peroxidase reagent in the presence of $\mathrm{H}_{2} \mathrm{O}_{3}$ and reducing Shiff's reagent (Sinke, Iijima and Hiraoka 1947). These results were confirmed later by the present author to be mostly the case with many higher plants except certain bulb plants (unpublished).

The writer wishes to acknowledge his indebtedness to Eme. Prof. Kuwada and Prof. Shinke of the Kyoto University under whose kindncss and encouragement the present investigation was carried out.

\section{Summary}

1. Division synchronization being taken as criterion, different cases of tapetum are classified into three types: 1) synchronized type, 2) asynchronized type and 3) intermediate type.

3). In the synchronized type second division takes place and further divisions may also occur. The final form is mostly of the periplasmodium type, with some few exceptions.

3. In the asynchronized type, the first division takes place, but no further divisions. The final form is exclusively of the secretion type.

4. In the intermediate type, two subtypes are distinguishable. In subtype 1 , second division takes place as in the synchronized type, and in subtype 2 , it does not as in the asynchronized type. In the intermediate type, both periplasmodium and secretion types are observed, and in subtype 1 , the periplasmodium type case is found in a greater frequency than the secretion type case, and in subtype 2 the two cases are found in the reversed ratio.

5. It is concluded that the tapetum which is of sporogenous cell complex origin would be the product of counteractions between the original character retaining tendencies and the tendencies converting toward somatic nature. The apparent two types are connected by intermediate cases to form a whole, so as to indicate that any classification should be artificial.

\section{Literature cited}

Bonnet, J. 1912. Archiv. f. Zellforsch. 7: 604.

Cooper, D. C. 1931. Amer. Journ. Bot. 18: 337.

Coulter, J. M. 1898. Bot. Gaz. 25: 713.

Farmer and Digby 1910. Ann. Bot. 24: 191.

Geitler, L. 1953. Protoplasmatologia 4:

Iijima, M. 1953. Cytologia 18: 113.

Lawson, A. A. 1904. Ann. Bot. 18: 417.

Meyer, K. 1925. Ber. Deutsch. Bot. Ges. 43: 108.

Mechelke, F. 1953. Chromosoma. 5: 246.

Pisek, A. 1923. Jahrb. f. wiss. Bot. 62: 1.

Szhnarf, K. 1923. Oster. Bot. Zeitsch. 72: 242.

Sinke, N., Iijima, M. and Hiraoka, T. 1947. Mem. Cell. Sci. Kyoto Univ. 19.

Smith, F. H. 1933. Amer. Journ. Bot. 20: 341.

Tischler, G, 1914, Jahr. f. Wiss. Bot. 55: 53. 